\title{
The Cure for Our Global Problems
}

\author{
J. T. Trevors • M. H. Saier Jr.
}

Published online: 31 May 2009

(C) Springer Science + Business Media B.V. 2009

As you read this editorial, over a billion of our fellow humans are existing under condition of extreme poverty and pollution (especially in large cities lacking proper infrastructure for potable water and waste treatment) without life's most basic necessities: food, water, shelter, clothing, and health care. They lack access to education and have essentially no rights. They suffer and die from "poor people's diseases" that seldom occur in more affluent communities. These diseases are largely preventable with diagnostic procedures and relevant drugs that are readily available in developed countries. Worst of all, the world's poorest people have no access to birth control. Hundreds of millions of impoverished women continue to bear children regardless of their inability to provide for them and their desire to limit the sizes of their families. Even abstinence is not an option for most of them, as they have neither choice nor voice in most aspects of their lives. We have the financial means to cure the diseases, provide unpol-

J. T. Trevors ( $₫)$

Department of Environmental Biology,

University of Guelph,

Guelph, ON N1G2W1, Canada

e-mail: jtrevors@uoguelph.ca

M. H. Saier Jr. $(\bowtie)$

Division of Biological Sciences,

University of California at San Diego,

La Jolla, CA 92093-0116, US luted potable water, reduce pollution, alleviate suffering, and prevent the premature deaths of poor people, but do we have the will? Developed countries collectively spend trillions of dollars annually on destructive warfare in the false belief that waging war will provide extra resources and make us more secure. Most recently, trillions of US taxpayer dollars have been allocated for economic bailouts, yet flawed policies and the rescued banks are the culprits behind the current global economic crisis. Research dollars are directed toward "diseases of excess"- the consequences of incorrect diets, obesity, and a lack of exercise. Why not spend some of these trillions to alleviate the misery and suffering of the poorest billion-plus humans in this world and reduce global pollution.

Most of us find the typical answer to this question unacceptable. When compassionate people hear the explanation that providing aid for the poor is not profitable for companies and investors, we feel compelled to respond: How can anyone be so callous, so inhumane? How little do these people believe a human life in a developing country is worth? From the manner wealth has been allocated in the past, one would have to conclude, very little. The same people probably also fail to comprehend the precarious condition of our biosphere and the total amount of global pollution. Their greed blinds them to the interdependencies of life forms in complex ecosystems. 
To illustrate the current situation, consider that you are in a gallery ablaze. You can save either a work of art valued at a million dollars or the life of a young child, not both. You must make a choice, and that choice will depend on your value system. Which is more valuable to you? Which will you choose to save? Only you can decide, and your decision will stem from your personal morals, emotions, and values. It is clear that some so-called political leaders have chosen with impunity when creating wars that killed thousands, or even millions of individuals - all people with a valid claim to life and liberty. So, why do the affluent countries and their citizens not assist the most needy people in our impoverished world? What do previous decisions say about our values as a nation when we care more about profit than human suffering? For some, suffering and the loss of life are simply accepted as normal unless they impact these individuals personally. A recent example is the swine flu (H1N1) pandemic threat. Dozens of preventable deaths in the poor regions of Mexico were of little immediate concern until a U.S. citizen died from the disease. These latter events triggered inordinately greater media attention than the former consequences of the disease.

While funding research, education, and family planning in underdeveloped countries may not be a sufficiently profitable endeavor for multinational corporations, provision is essential for societal stability, and need not involve appreciable sacrifices by wealthy countries. We could divert some of the resources currently expended to wage war toward efforts that actually benefit humankind. In other words, these funds could be used to create peace and relieve suffering rather than the opposite. We could provide financial aid for family planning that is not contingent on national economic policy concessions. The wealthy, those most able to contribute, must recognize their responsibilities to society. The financial impact of their participation will be personally negligible compared to the consequences of doing nothing. Efforts to alleviate poverty will produce a far bigger "bang for the buck" in achieving national security than waging war, which has no easily recognized beneficial consequences. On the other hand, stabilizing the human population has the potential to result in true sustainability-our best hope for future generations. Without such achievement, there can be no such hope.
As we write this editorial, the world's economy is in a downward spiral while global climate change and environmental pollution threaten our biosphere. Still, war-mongers, the high-testosterone bullies of the world, continue to inflict misery and death on people who, in different circumstances, could be our allies in a cooperative effort to help resolve our mutual, crucial, global challenges. Making things worse, and of utmost importance, the growth of the human population is not being addressed.

When one elite segment of our population has the technology and financial means to solve the crises humanity faces, but does not act responsibly, the entire planet is endangered. If we fail to act, we must conclude that the system is morally and ethically bankrupt. The media and politicians can focus on the stock market, bailouts, and stimulus plans, but they are not addressing the core of the problem. The system needs to be corrected, starting with a redirection of resources, away from war and unbridled greed, and towards synchronized global environmental and economic sustainability.

Do not expect our elected officials and dictators to go willingly down the only path that leads to a just and sustainable global future. There are too many golden handcuffs tying them to the present system. It is up to us to make the case so compelling that they cannot ignore it. We must demand that they recognize their responsibilities. They and we must provide the aid needed in poor countries, particularly with respect to birth control, family planning, poverty, hunger, and decreasing pollution of the biosphere. Without family planning, women in these countries will have no freedom, and the natural resources per person will continue to decline. Hundreds of studies show that there are already far more humans on this planet than the earth can sustain. Without a concerted effort to educate couples and empower women so they can control their own lives and their family sizes, there will be no solutions. We will have to continue to face a future with massive human misery and unrest. Wars for limited resources will continue to accelerate resource depletion until massive numbers of human deaths will allow the Earth to return to a state of sustainability. In the not so distant future, sustainable may really mean survival. We can only hope that reason will prevail and avert such a shameful waste of human potential! 